\title{
Review of Severe Deformation Recommended Practice Through Analyses - Comparison of Two Cab Car End Frame Designs
}

\author{
Eloy Martinez \\ David Tyrell \\ John Zolock \\ Volpe National Transportation Systems Center \\ Jacques Brassard \\ Bombardier
}

\begin{abstract}
Non-linear large deformation analyses have been conducted to evaluate the performance of the cab car corner and collision posts of the Federal Railroad Administration's (FRA) sponsored state-of-the-art (SOA) end frame design and the Bombardier M7 design under quasi-static and dynamic test conditions. Pre-test analysis predictions of the dynamic performance of the SOA corner post closely match test measurements. A similar analysis of the corner post was performed on the M7 design, and the results compared with the SOA test and analysis results. Using this M7 model, analysis results for the quasi-static test of the collision post were developed, and compared with the test measurements. Up to the onset of material failure, the analysis results and test measurements closely agree. After the onset of material failure, the results progressively diverge. Overall, the crashworthiness performance of the collision posts of the SOA and M7 designs were found to be essentially the same, and the performance of the M7 corner post design was found to perform better than the SOA corner post design. This difference in performance comes from the sidewall support in the M7 design, which is not present in the SOA design.
\end{abstract}

\section{INTRODUCTION}

In support of the Federal Railroad Administration's (FRA's) Equipment Safety Research Program the Volpe National Transportation Systems Center is conducting analyses of cab car end frame designs subjected to offset collision conditions similar to those experienced at grade crossings. North American commuter trains come in two categories. The first category of commuter trains is multiple-unit (MU) trains, where each car is self-propelled. The second category is push pull trains, where there is a locomotive at one end of the train, which pushes unpowered coach cars when operated into the city center, and pulls the coaches away from the city center. MU cars typically have cab cars at each end of the train, which has an operator's control stand. In a push-pull train, there is a $\mathrm{cab}$ car at the end of the train opposite the locomotive. Cab cars are more vulnerable during a collision due to their relatively light weight and lower underframe strength compared with a locomotive. During an offset impact condition the cab car end frame is the only structure between the operator and the intruding object. It is vitally important that the end frame behave in a ductile manner absorbing some of the collision energy while maintaining sufficient space for the operator to ride out the collision.

Both the Federal government and the passenger railroad industry are aware of the dangers associated with cab car operations. To address these concerns the FRA promulgated passenger equipment safety standards in May 1999 that covered end frame requirements as well as other crashworthiness related concerns [1]. The American Public Transportation Association (APTA) also issued an industry standard in 1999 that included additional requirements on end frame designs [2]. These standards included both increased strength requirements for the cab car vertical end frame members -- collision and corner posts as well as deformation requirements. The deformation requirements required that the end frame vertical members must be able to sustain 'severe deformation' before failure of the connections to the underframe and roof structures.

In initial attempts to apply the APTA standards to new equipment, the car builders and the operating authorities were unable to come to mutual agreement on an objective definition of 'severe deformation,' and consequently were unable to agree if particular designs met what was intended by the standard. APTA subsequently removed the term 'severe deformation' from the standard text and re-issued it under a recommended practice until the technical issues associated with defining acceptable acceptance criteria could be resolved [3]. Full-scale impact test results have shown that cab car crashworthiness can be increased with requirements for severe deformation [4]. The FRA has requested the Railway Safety Advisory Committee 
(RSAC) [5] to develop recommendations on passenger train crashworthiness, as well as recommendations on other passenger rail safety issues. The purpose of this paper is to summarize the work done to date of the technical information to make recommendations for regulations requiring the graceful failure of corner and collision posts of cab car end frames when overloaded.

This paper presents results obtained from quasi-static and dynamic full-scale testing on M7 collision post and on SOA corner post respectively as well as large deformation analysis in the post buckling regime of cab car end frame designs subjected to both strength based requirements as well as newly proposed performance based requirements. Two designs were studied in detail: an FRA-sponsored prototype state-of-the-art, SOA, designed to optimize severe deformation capability and retrofitted onto a Budd Pioneer passenger cab car and the Bombardier M7 cab car design currently in use by Long Island Railroad and Metro North Railroad. Both designs complied with all applicable Federal regulations, [1], and APTA standards, [2].

The organization of the paper is as follows: first the motivation for the study is presented; followed by the discussion of the full-scale quasi-static "mock-up" test of the M7 collision post and FE analysis of the corner post loading; next the full-scale dynamic grade crossing test of the SOA corner post is discussed; the results from comparative analysis of both designs are discussed; and finally a summary of the key findings is discussed.

\section{MOTIVATION FOR CAB CAR END FRAME DESIGN STUDY}

The use of cab cars subjects the operator to risk in the event that the cab car strikes an object that fouls the train's right-ofway, ROW. An example of such a collision occurred in Portage, Indiana in 1998 where a Northern Indiana Commuter Transportation District (NICTD) train with a cab car in the lead position struck a tractor-tandem trailer carrying steel coils stuck on the grade crossing [6]. Figure 1 shows an exterior view of the cab car, an interior view of the cab car, and a picture of the steel coil that penetrated through the end frame into the passenger compartment. In this accident the cab car impacted the steel coil centered on one collision post. The collision post failed and allowed full penetration into the interior of the passenger car. There were subsequently several injuries and three fatalities associated with bulk crushing of occupants by the coil.
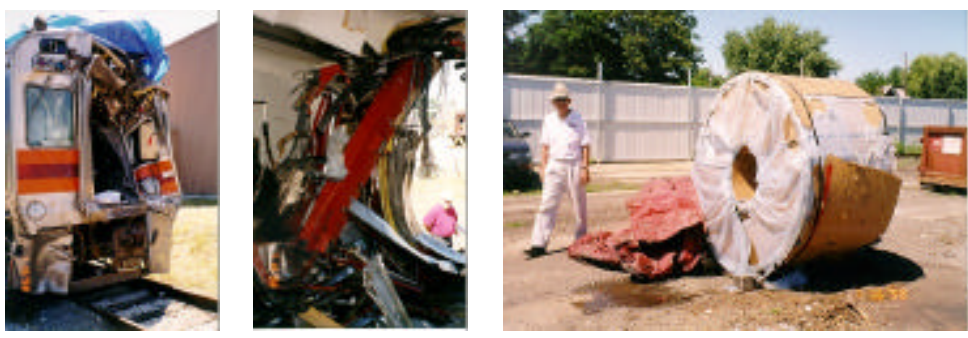

Figure 1. Grade Crossing Accident in Portage, IN, 1998
The roof attachment and the post itself apparently failed with very little deformation of the post. Additional examples of incidents where the end frame was engaged and a loss of operator survivable volume ensued are: the 1975 Yardley, Pennsylvania collision between a cab-car-led commuter train and a tractor semi-trailer carrying coils of steel [7], the 1996 Secaucus, New Jersey collision between a cab car led consist with a locomotive led consist at a switch [8], the 1996 Silver Spring, Maryland collision between a cab car led consist with a locomotive led consist at a switch [9], and the recent 2004 Metro North collision of a cab car led consist with a crane fouling right-of-way.

It should be noted that these impacted car designs only satisfied the minimum FRA requirements and not the present APTA standards for strength and attachment requirements. Although the speeds associated with some of these events are greater than what can be protected against, they serve as indicative loading conditions against which enhanced designs can improve performance.

\section{M7 CAB CAR QUASI-STATIC FULL-SCALE SUB- ASSEMBLY TESTING}

Bombardier conducted a series of qualifying quasi-static tests on a mock-up front end structure of an M7 cab car. In total, four tests were conducted on the front end structure: a $100,000 \mathrm{lbf}$ load applied longitudinally on the corner post at 18 inches above the top of the end sill, a 100,000 lbf load applied transversally on the corner post at 18 inches above the top of the end sill, a load up to the elastic limit of the collision post applied longitudinally at a distance 30 inches above the end sill, and an ultimate load case applied 30 inches above the end sill. The first three loads were elastic in nature and the last load case was designed to evaluate the large deformation collapse response of the collision post.

The mock-up test article was developed for the F-end of an M7 cab car. The first 19.25 feet of the car was fabricated with great fidelity between the car's body bolster and the extreme most front end. The mock-up contained all structural elements, but did not contain the corner post rub plates, the plymetal floor, any interior finishing, windows, doors, bonnet, etc.

The mock-up test article was installed in the testing bay and supported vertically in 4 locations along the side sills. The supports were located at the rear of the mock-up and 70 inches behind the end sill. The longitudinal supports were located at the rear of the mock-up at the side sills and the roof rails. In addition the mock-up was restrained laterally at each corner for stability reasons against the jig longerons. Figure 2 is a schematic of the test set-up used.

Four 500,000 lbf load cells were situated at the rear longitudinal support positions to measure the loads. A 400,000 lbf hydraulic jack was used to input the longitudinal load into the collision post over a bearing plate that helped to distribute the load. The bearing plate dimensions were 10 inches wide by 4.75 inches high by 1.5 inches thick. The increased width of the bearing plate was to prevent a bearing failure of the collision post outermost flange. 


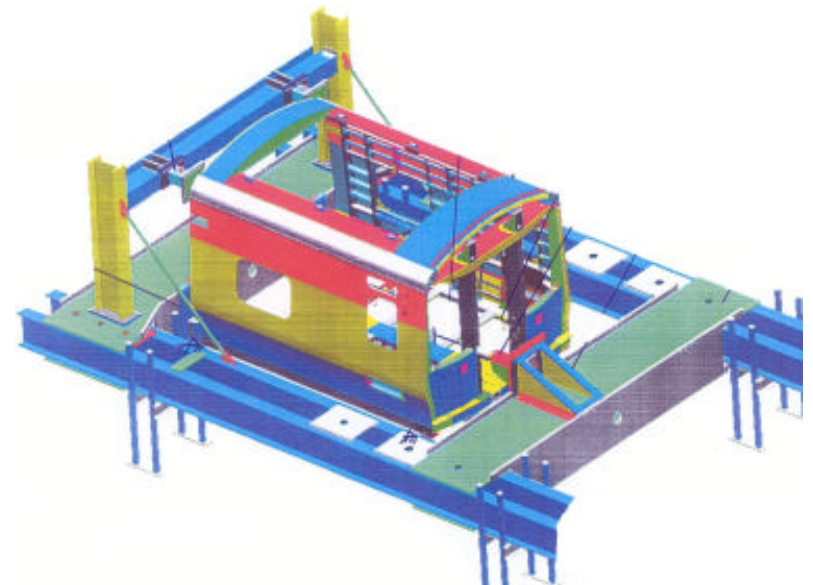

Figure 2. Schematic of Testing Set-up for the M7 Cab Car Collision Post Load Case

Five LVDT displacement transducers were used to measure the collision post deflection at the following heights above the end sill: 1 inch, 5 inches, 30 inches, 42 inches, and 82 inches. In addition to the displacement transducers, 100 strain gauges were placed at various positions on the structure to measure the load path through the carbody frame including on the following key structural elements: the collision post, the corner post, the intermediate shelf structure that ties the collision post to the corner post just below the window, the anti-telescoping plate, and various additional longitudinal members. All instrumentation was calibrated prior to each test.

The load was ramped up slowly through a number of load increments. The strains and the load deflection characteristics were checked for non-linearity to establish the elastic limit. After the elastic limit was reached, the load was recorded at increments where the deflection increased by 0.5 inches. This process was continued until the collision post was able to sustain a load greater than $200,00 \mathrm{lbf}$.

The metrics used to determine whether the test was successful are:

- For linear elastic behavior, the force deflection characteristic can not vary from a linear relationship by $+/-5 \%$ with one point taken at the origin and the second the maximum load recorded

- For the linear elastic behavior, the strain plotted against the load can not vary from a linear relationship by $+/-5 \%$ with one point taken at the origin and the second the maximum load recorded

- Residual strains on key structural elements must be less than $100 \mu \varepsilon$ after removal of the maximum elastic load

- The ultimate plastic load must be greater than 200,000 lbf

- The maximum deflection at the ultimate plastic load must be greater than $50 \%$ the depth of the collision post

- The connections between the collision post and all structural members must not be broken (that is experience material failure where complete separation of attachments occur)
The results from the linear elastic testing indicate that the collision post's elastic limit is reached when the load reaches $143,700 \mathrm{lbf}$ for the load applied at 30 inches above the end sill distributed over the bearing pad. A series of strain gauges was used to determine whether the collision post material on the tension flange near the load application point exceeded the material's yield strength. Strain gauges were located around 32 inches above the end sill. Additional strains were reviewed at other locations on the collision post as well as on the end sill and the anti-telescoping plate. The post was constructed from an A710 material and the actual material's yield strength was used. Both the load deflection and strain load plots remained linear within the allowable range defined up to this load level. The maximum deflection in the collision post before yielding occurred at the LVDT positioned at 42 inches above the end sill. The deflection was 0.334 inch. As expected, this deflection occurred in an area of the collision post where the shear reinforcement ends.

The results from the ultimate plastic load application at 30 inches above the end sill are shown in Figure 3. This is a plot of force deflection where the maximum load of $365,150 \mathrm{lbf}$ is reached at a deflection of 1.23 inches. The force level subsequently softens and the load was removed from the structure at 7.0 inches of crush with the load at 211,000 lbf. The same deflection gauges were used for the linear elastic test and the maximum deflection, 8.5 inches, occurred at the $42-$ inch height on the post. The load deflection is shown in Figure 3.

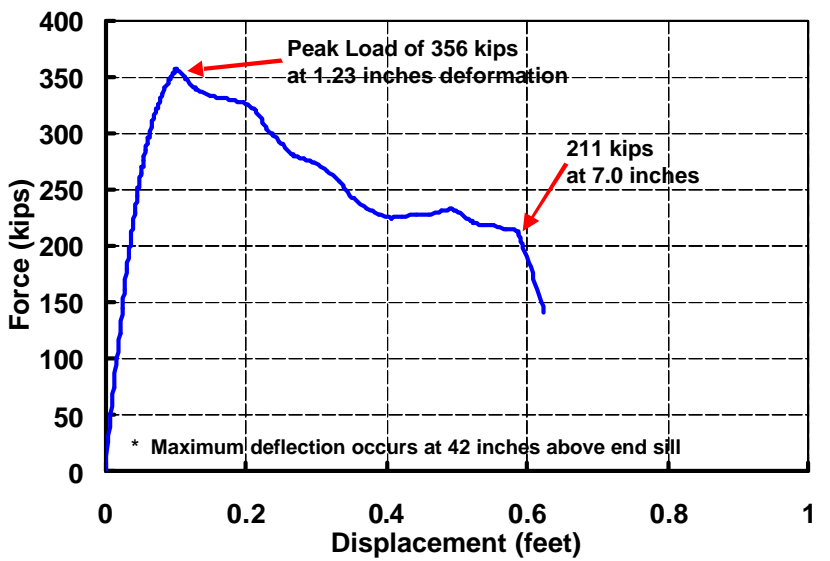

Figure 3. Force Deflection of M7 Cab Car Collision Post Loaded 30 inches Above the End Sill

The post-test inspection did show some material failure occurring in various components. Some failure occurred in the collision post at 42 inches above the end sill in the tension flanges and the compression flanges experienced significant plastic flow. This is where the central hinge forms under this loading condition. Additionally there were plastic deformations at the load application area. Progressive fracture occurred at the base of the collision post during later stages of deformation, which resulted in the termination of the test for safety reasons.

The structural shelf broke at its connection with the collision post. The decision was made to reinforce the 
connection for production end frames, to reduce the likelihood of the connection failing under such load conditions. The bulkhead sheet pulled out the end sill top plate. In addition the end sill bottom flange buckled between the collision post and the end sill end plate. Finally, the anti-telescoping plate was pulled down 3 inches. Figure 4 shows several views of the final deformed shape of the collision post.
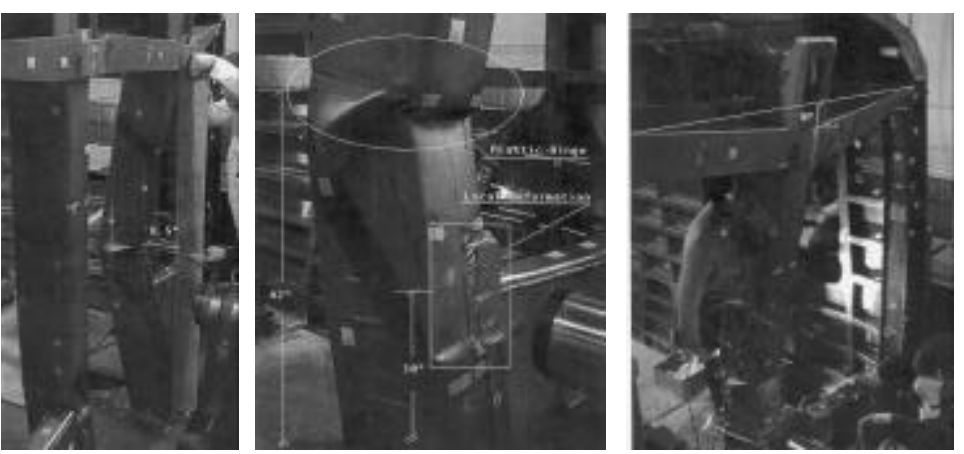

Figure 4. Post-Test Deformed Shape of M7 Cab Car Collision Post Loaded 30 inches Above the End Sill

\section{SOA CAB CAR DYNAMIC FULL-SCALE TESTING}

The full-scale grade crossing impact tests were conducted as part of a series of crashworthiness tests of passenger rail equipment. The overall objective of this series of tests is to evaluate incremental improvements in the crashworthiness performance of modern corner post designs when compared against the performance of older designs [10, 11, 12]. The grade crossing tests were designed to address the concern of operator vulnerability to bulk crushing resulting from offset/oblique collisions where the primary load resisting structure is the end frame design. Two grade crossing tests were conducted in June 2002 and in both tests a single cab car retrofitted with an end frame design impacted a steel coil resting on a frangible table at a nominal speed of $14 \mathrm{mph}$ [13, 15]. The 40,000 lbf steel coil was situated such that the coil impacted the corner post of the cab car above the end sill. Figure 5 is a schematic of the grade crossing test.

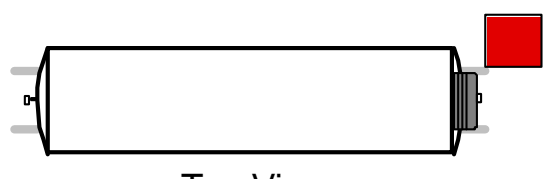

Top View

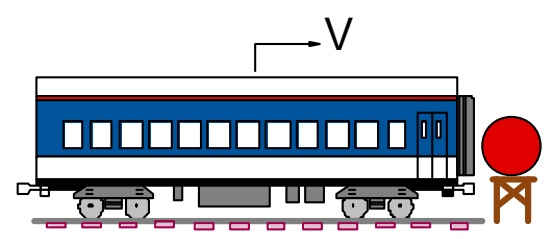

Elevation View

Figure 5. Schematic of Grade Crossing Collision Test

Figure 6 shows a photograph of the test setup for the developed prototype SOA end frame design. The car was instrumented to measure the accelerations of the carbody, the displacements of the suspensions, the displacement of the corner post, and the strains in selected structural members. The coil was instrumented to measure the three dimensional accelerations including the yaw, pitch, and roll. On-board and wayside high-speed film and video cameras were used to record the impact. Details of the instrumentation requirements for the test are in [13]. A locomotive was used to push the cab car up to speed and then released; the cab car subsequently struck the steel coil.

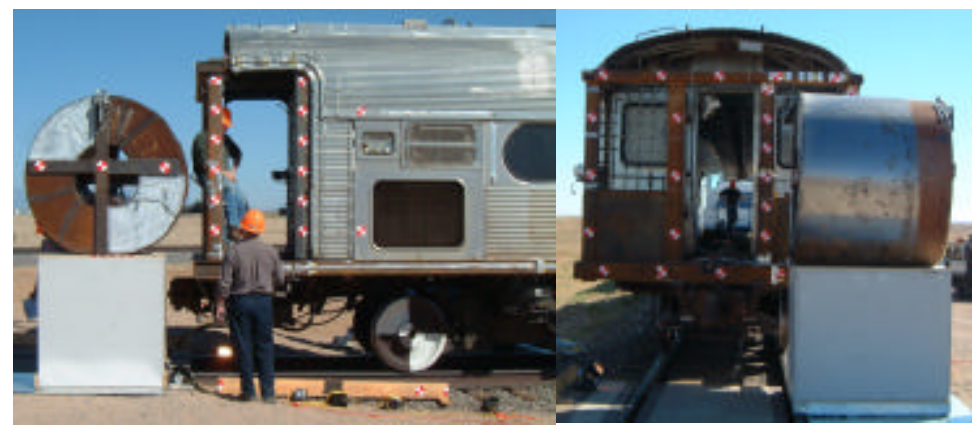

Figure 6. Grade Crossing Scenario Dynamic Impact Test Set-Up for SOA End Frame Design

The results from the prototype SOA end frame testing is that the crush was restricted to less than 12 inches of inward deformation thereby preserving space for the operator to safely ride out the collision. The incremental increase in safe closing speed as compared to the minimum FRA design also tested is from $11 \mathrm{mph}$ to $15 \mathrm{mph}$. A post-test photograph of the SOA cab car is shown in Figure 7. Although there is some material failure present, no connections have fully failed for a crush distance just less than 9 inches.
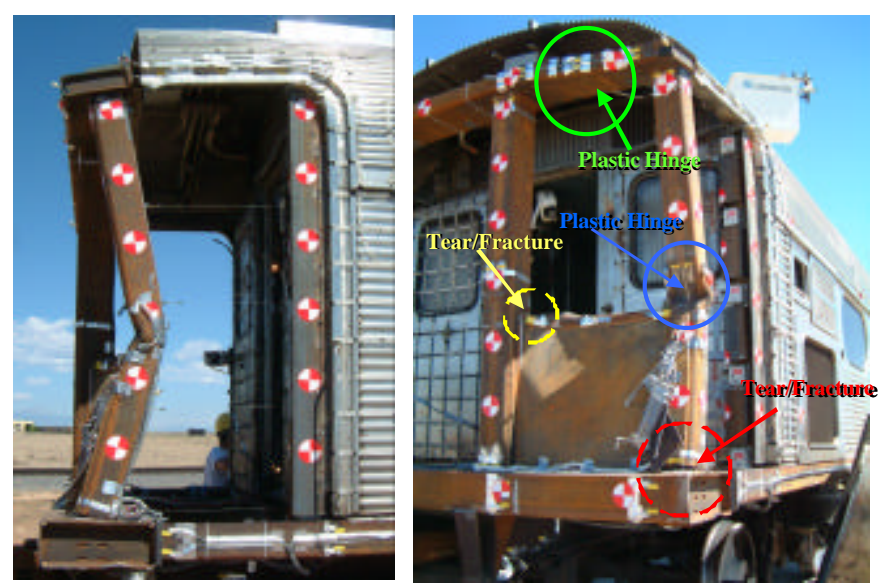

Figure 7. Post-Test Deformed Shape of Prototype SOA End Frame Design

Figure 8 shows three still photographs taken from a highspeed film of the test of the SOA design. The first frame shows the coil and corner post at the instant of impact, the second frame shows the coil and the cab car after approximately 0.03 seconds and 5.25 inches of rearward displacement of the corner post. The third frame shows the coil and the cab car after approximately 0.08 seconds and 9 inches of displacement of the 
corner post. In the test, the corner post acted largely as a fixedpinned beam that is overloaded. A plastic hinge formed early in the test near the center of impact. As the test progressed, the corner post bent into a ' $\mathrm{V}$ ', which put a significant tension load on the corner post. Both the upper and lower attachment of the corner post had to support the shear load from the coil and the tension load due to the bending of the beam. The end beam did not visibly plastically deform, and so the floor attachment acted as a fixed connection. The anti-telescoping plate and the cant rail did deform downward, and consequently the roof connection of the corner post acted as a pinned connection.

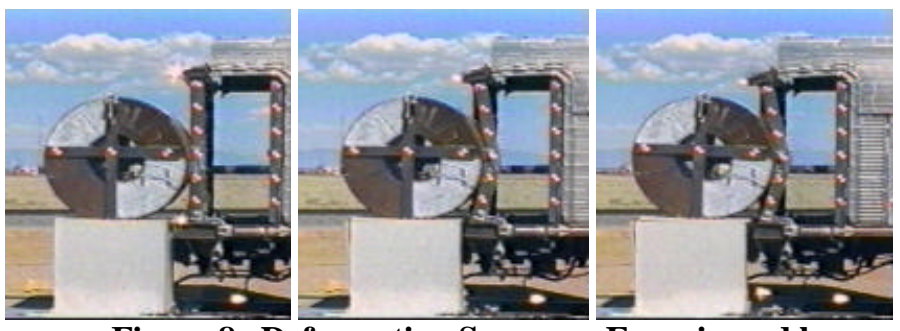

Figure 8. Deformation Sequence Experienced by Prototype SOA End Frame Design

Material failure occurred in the SOA end frame design test at the connection of the corner post to the end beam, at the attachment of the anti-telescoping plate to the cant rail, and at the attachment of the lateral member/ shelf to the collision post. The areas where failure occurred are visible in Figure 7. The failure at the base of the corner post progressed nearly the full depth of the post. The material failure that occurred at the antitelescoping connection with the cant rail was in the region of a weld. The last area with material failure is at the connection point of the bulkhead sheet with the lateral member/shelf and the collision post. The failure proceeded from the outside of the car inward and then downwards between the collision post and bulkhead sheet weld.

The unfiltered force crush characteristic determined for the corner post response is depicted in Figure 9. The force was obtained by using the resultant acceleration obtained using the 9 accelerometer array on the steel coil and multiplying this value by the mass of the coil. The required load level at 18 inches above the end sill is 100,000 lbf without permanent deformation. The bending moment generated by the steel coil load is much higher and occurred in the plastic domain. The peak load resisted is approximately $275,000 \mathrm{lbf}$. This load level occurred at 6 inches of inward deformation. The greatest crush distance measured was 9.5 inches, but the final crush distance measured was 8.5 inches. The corner post experienced some elastic recovery upon rebound of the coil.

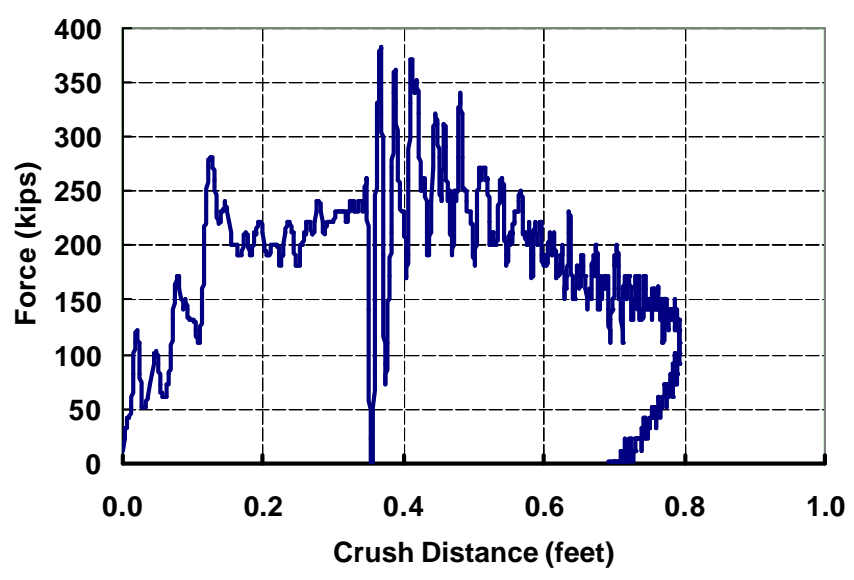

Figure 9. Measured Dynamic Force Crush Characteristic for the Prototype SOA End Frame Design

\section{COMPARATIVE NUMERICAL RESULTS}

Prior to conducting the full set of collision scenarios of concern on both the prototype SOA and the M7 cab car end frame designs a number of comparative analyses were conducted of the quasi-static and dynamic tests to determine the fidelity of the models used. Once the models were compared against test conditions the offset grade crossing scenarios were investigated with a rigid coil being impacted centered on either the collision or corner post above the end sill for both designs. The details of the two models are discussed in the Appendix.

\section{M7 Quasi-Static Model and Test Results}

The results from the quasi-static large deformation plastic load application of the collision post of the M7 cab car are in good agreement with the deformed shape observed during the test. The model captures the deformation modes of the key structural elements that make up the integrated end frame very well. The model is also capable of predicting those areas where it is expected that material failure will occur. Figure 10 and 11 show comparative test photographs with model results.
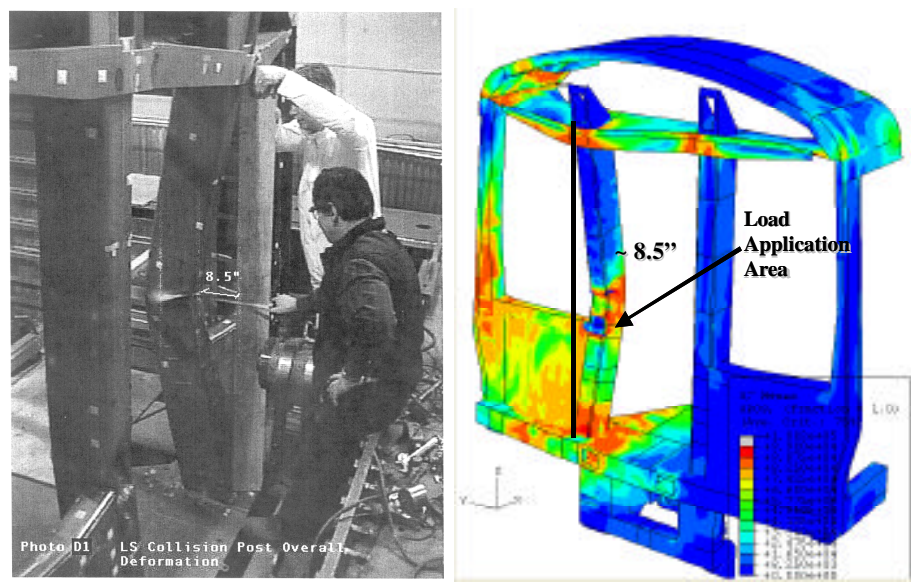

Figure 10. Comparison of Observed Quasi-Static M7 Cab Car Collision Post Deformation with Predicted FEA Model Results 

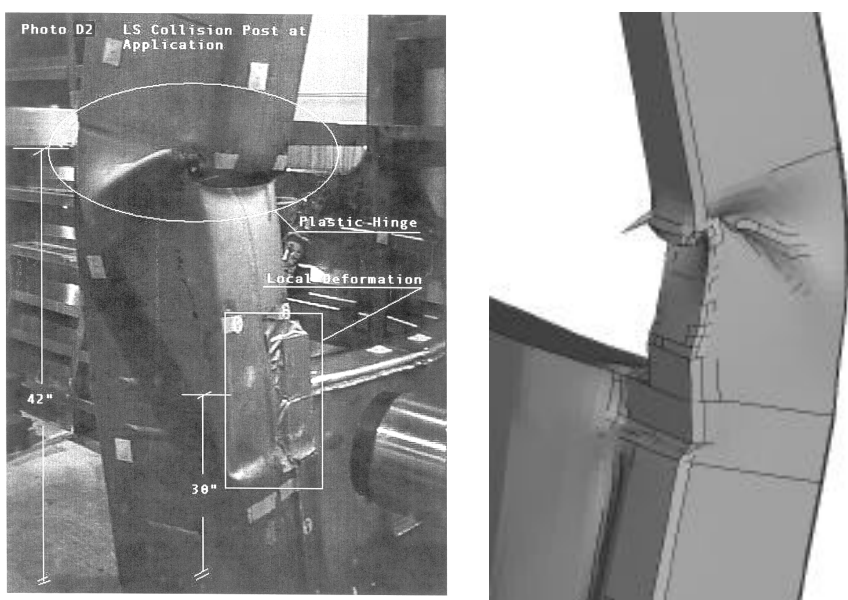

Figure 11. Close-Up Comparison of Load Application Area and Central Plastic Hinge

Using nominal material properties for the end frame components resulted in under estimation of the test results. The nominal properties were increased by ten percent to better capture the peak force at the appropriate crush distance and the overall force crush trend for the full crush distance. There is good agreement with the force crush characteristic prior to post-buckling softening. For larger crush distances, the model tends to over predict the force levels exhibited by the structure, but the trend is maintained. The force crush characteristic is depicted in Figure 12. It has been shown that the variation in the peak force derived from test measurements can be as much as 140 percent for ostensibly identical structures crushed under similar test conditions; it also has been shown that the variations in average force computed from test data can be approximately 20 percent [14]. The results obtained from the finite element model were considered sufficient to now use the same developed model for running the offset grade crossing collision scenarios.

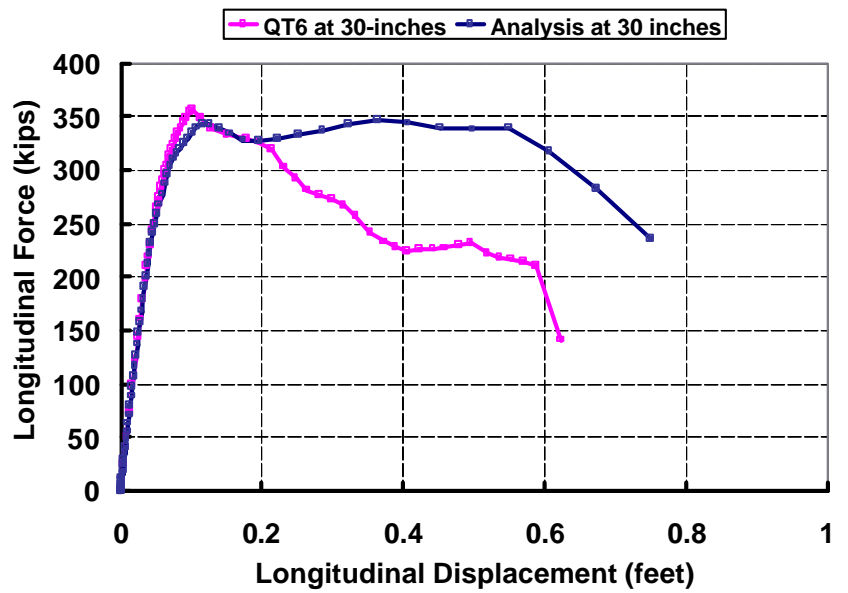

Figure 12. Comparison of Force Crush Characteristics for Collision Post Loading 30 inches Above the End Sill

\section{SOA Dynamic Model and Test Results}

The same pre-test model was used for the prototype SOA design that is discussed in more detail in [15]. Figure 13 depicts a comparison of the deformation sequence observed in the full-scale grade crossing test with the predictions using the pre-test finite element model. The pre-test model had excellent agreement both with the force crush characteristics measured but also with the modes of deformation and failure. Figure 14 depicts the comparison of the force crush characteristics measured and predicted. This model was considered sufficiently validated that it can now be used directly in running the offset grade crossing collision scenarios.
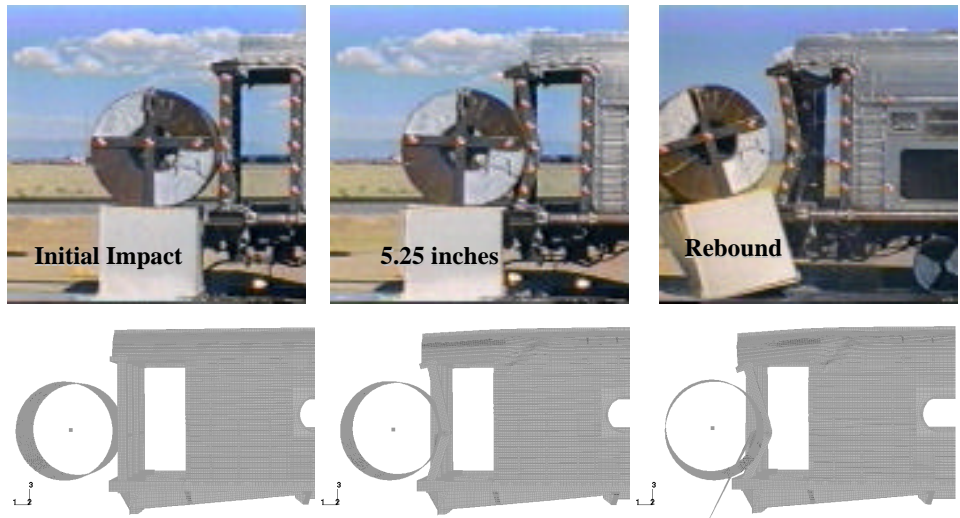

Figure 13. Comparison of Pre-Test Model Deformation Sequence with Observations from Full-Scale Grade Crossing Corner Post Impact Test

Having established the fidelity of the two models to a certain level, the dynamic performance of the two designs is now compared. The purpose of these calculations are to understand the modes of deformation of the individual components loaded and the reaction of the load through the attachments, predict where material failure initiation should occur, and compare the force crush characteristics.

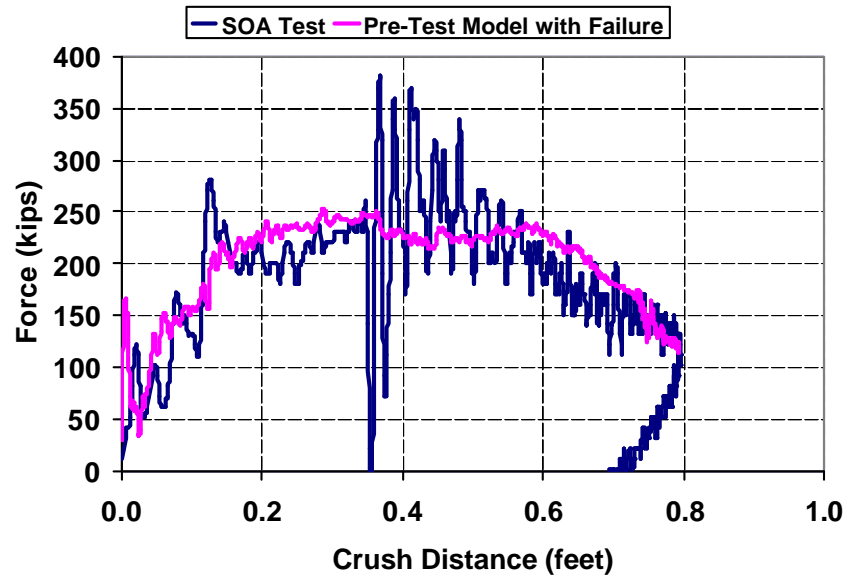

Figure 14. Comparison of Pre-Test Model Predictions and Measured Force Crush from the Full-Scale Grade Crossing Corner Post Impact Test 
The collision scenario defined is that of an offset loading condition where a moving cab car strikes a rigid steel coil. The choice of a steel coil as an impacting object stems from the desire to establish the inherent capacity of the end frame design. Using a deformable impacting object adds the complication of accounting for energy absorption of both the end frame design as well as the impacting object. The coil is situated such that the impact is centered on either the collision post or the corner post two inches above the buffer/end beam. The steel coil weighs 41,300 lbf. The diameter of the steel coil is 62.5 inches and the length of the coil is 52 inches. Detailed model descriptions are in the Appendix.

The discussion will start with the results from the prototype SOA end frame design. The performance of the corner post behavior to this impact loading condition is described in more detail in $[13,15]$ and was summarized above. Therefore the corner post results will not be discussed further. However, the corner post model was re-run with a higher initial impact speed to get results at greater crush distances.

\section{SOA Dynamic Collision Post Model}

The results from the collision post loading are that prior to complete failure of the connection with the buffer/end beam the collision post deforms 11.5 inches. There is still residual capacity of the structure due to the degree to which it is integrated with the rest of the end frame. The bulkhead sheet continues to shed load to the corner post and into the buffer/end beam. The calculation was stopped after 12 inches of crush, which was the maximum allowed crush distance. Figure 15 depicts the deformation sequence for the collision post loading condition of the prototype SOA end frame design.

Comparisons of the force crush characteristics for both prototype SOA end frame design collision and corner posts are shown in Figure 16. The force crush characteristics were determined by cross-plotting the longitudinal displacement after initial contact of the steel coil against the acceleration multiplied by the mass of the steel coil. The shape of the two curves is very similar for the 12 inches of crush shown. However, the collision post characteristic is elevated in comparison with the corner post. This is due to two important factors: the collision post is larger than the corner post and the anti-telescoping plate connection to the adjacent collision post helps to distribute significant load into the rest of the end frame. The blue diamond figure on the plot demarcates the location where failure of the shelf/lateral member experiences complete failure. The two octagon figures on the plot demarcate the crush distance at which failure at the connection with the buffer/end beam initiates.
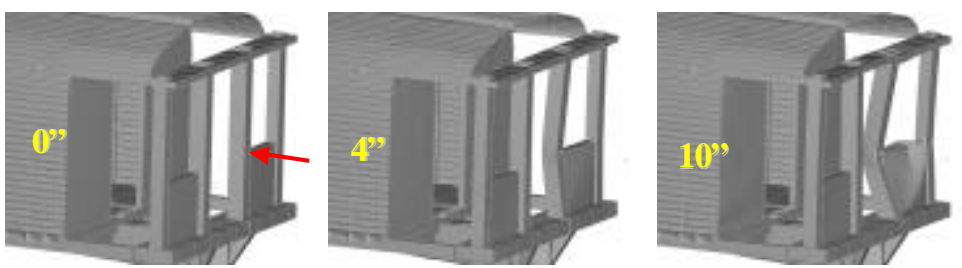

Figure 15. Predicted Deformation Sequence of the Prototype SOA End Frame Under the Dynamic Offset Collision Post Loading
As is apparent from both the deformation sequences shown in Figures 13 and 15. The collision post is 7.75 inches deep while the corner post is 6.625 inches deep. The displacement of full failure of the either post respectively at the connection with the buffer/end beam is 11.5 inches and 11.1 inches respectively. These distances are the reported distance the steel coil displaces inward after initial contact with the end frame.

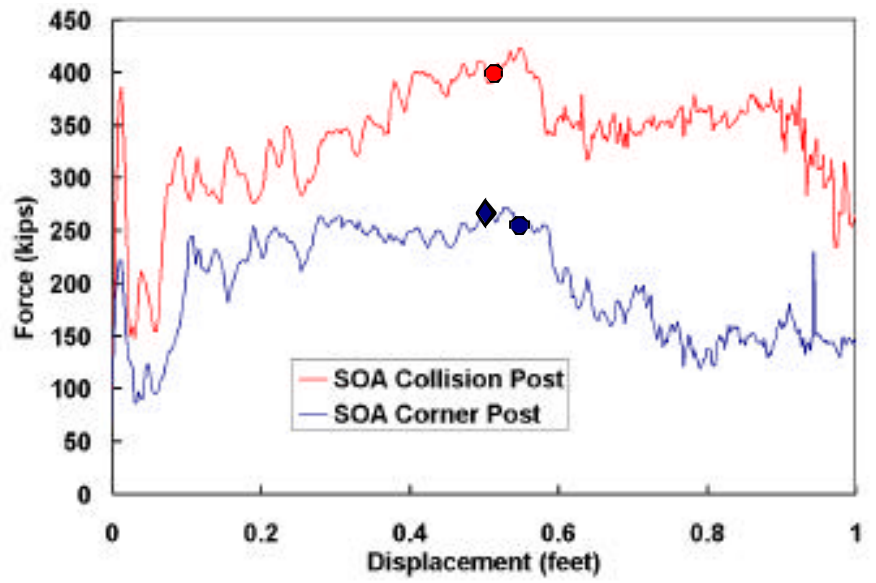

\section{Figure 16. Comparison of the SOA Collision and Corner Post Force Crush Under the Dynamic Loading Condition}

\section{M7 Dynamic Collision Post Model}

The results from the M7 cab car collision post analysis is that complete failure of the connection of the collision post with the end sill does not occur until 13.1 inches of deformation. Similar to the SOA design there is some additional capacity due to the presence of the bulkhead sheet and the connection through the anti-telescoping plate. The results are only plotted out to 12 inches of crush, which corresponds to the allowable degree of inward deformation to maintain occupied volume. The deformation sequence for this analysis case is shown in Figure 17. The three stages shown are initial impact, 4 inches of crush, and 10 inches of crush. The red arrow demarcates where the coil is initially impacted. The deformation pattern is similar as that predicted and observed from the quasi-static tests. The position of greatest inward deformation occurs at roughly 42 inches above the end sill where the shear reinforcement ends. Additionally the shelf/lateral member connection failed. There is a similar lateral torsional deformation of the anti-telescoping plate as well.
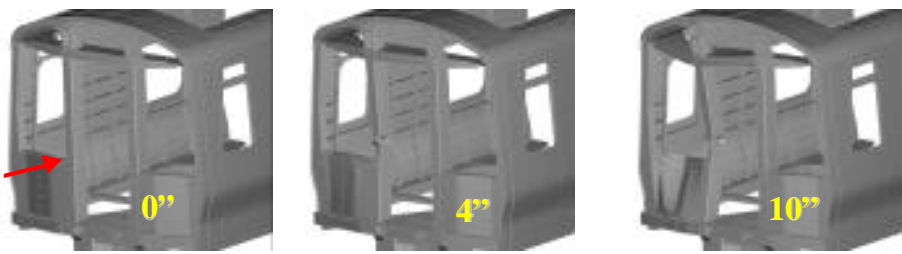

Figure 17. Predicted Deformation Sequence of the M7 End Frame Under the Dynamic Offset Collision Post Loading 
Prior to showing the force crush characteristic for the M7 collision post loading it is helpful to first describe the results from the corner post loading condition. The performance of the corner post is better than that observed for the SOA corner post design due to the presence of the support provided by the wall sheathing and longitudinal stiffeners. The M7 corner post experiences 11.9 inches of inward deformation at complete failure at the bottom of the post just above the end sill. The deformation sequence for this analysis case is shown in Figure 18. The three stages shown are initial impact, 4 inches of crush, and 10 inches of crush. The red arrow demarcates where the coil is initially impacted.
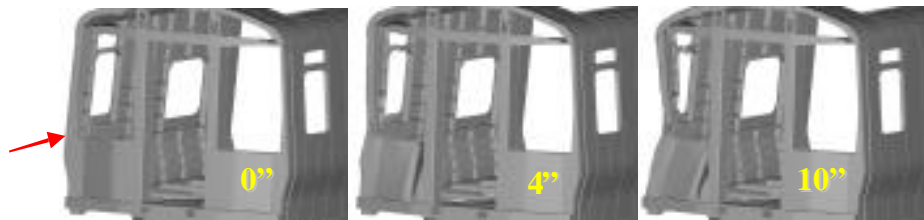

Figure 18. Predicted Deformation Sequence of the M7 End Frame Under the Dynamic Offset Corner Post Loading

Figure 19 is a plot of the force crush characteristics predicted from the two M7 loading conditions discussed. The pink and red diamond figures on the plot demarcate the crush distances for each loading condition where the shelf/lateral member starts to fail. The collision post was pushed inwards 6.7 inches and the corner post was pushed inwards 7.0 inches. The octagon figures demarcate the crush distances that failure at the base of the post initiates. The crush distances for the collision and corner post at complete failure are 13.1 inches and 11.9 inches of inwards deformation respectively. Testing is considered to further validate these results.

The collision post is of a box beam construction that is 10 inches deep. The corner post has a variable size cross-section but is 6.1 inches deep at the connection with the end sill.

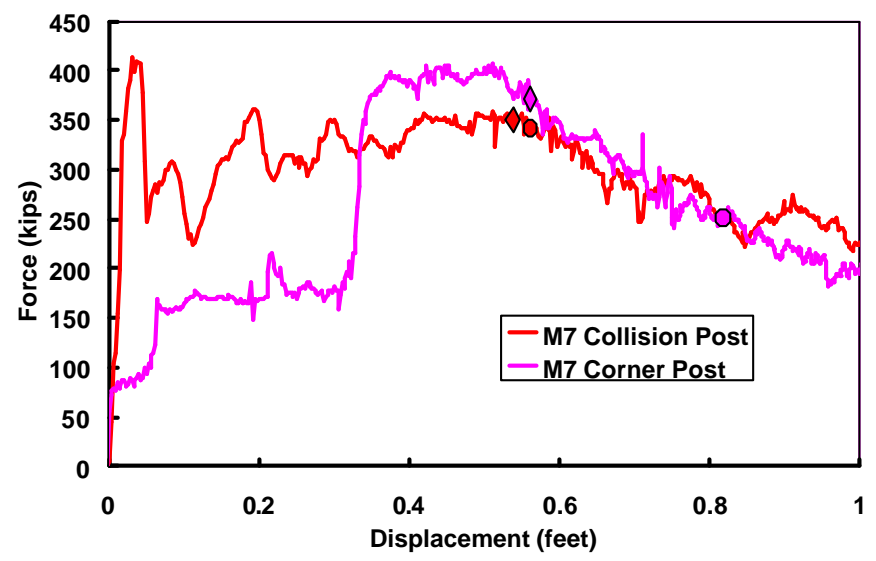

Figure 19. Comparison of the M7 Collision and Corner Post Force Crush Under the Dynamic Loading Condition

\section{DISCUSSION}

Both designs make use of a box beam for the buffer/end beam on the SOA design and end sill on the M7 design. The M7 end sill is somewhat tapered for curving allowances. The M7 collision post is larger than the SOA collision post. The difference in depths is 10 inches versus 7.75 inches and in width is 6.0 inches versus 7.25 inches. Note that the narrower M7 collision post design allows for optimum driver visibility through the windshield and to meet ADA requirements. The corner posts are also different in that the M7 design has a shaped variable cross-section post while the SOA design is a simple box beam. The collision and corner posts from both designs penetrate through both flanges of the respective buffer/end beam or end sill. This is an important similarity in that this type of connection through a box beam exhibits excellent resistance to both bending and torsional loads.

Both designs have an intermediate shelf/lateral member of similar strength just below the forward facing windows. In addition both designs make use of a bulkhead sheet that is integrally tied to the buffer/end beam, the collision post, the corner post, and the shelf/lateral member. This bulkhead sheet is present to help prevent intrusion of foreign objects and serves as a spall shield. The M7 corner post is reinforced with the outer wall sheathing and longitudinal wall stiffeners from the end sill to the cant rail whereas the SOA design is without such lateral reinforcement. This has a significant effect on the performance of the M7 design. The lateral support that the wall provides enhances the crush resistance of the corner post as visible in the later stages of crush in Figure 19.

Another significant difference between the two designs is the shape of the anti-telescoping plate. The M7 design antitelescoping plate is an open section while the SOA's is a closed internally reinforced box beam. The box beam is very efficient in resisting torsional and bending loads while the open section is less efficient but allows for equipment installation in that area. Finally, the last key difference between the two designs is the size and shape of the cant/roof rail. The M7 has an enclosed box beam through which the corner post is attached at the bottom of the anti-telescoping plate to resist special loads such as diagonal jacking while the SOA design has a very light open section that connects to the rear web of the antitelescoping plate.

Despite these design differences, both designs provide improved crashworthiness protection for the operator under the described collision scenario. The simulated crashworthiness performance of the collision posts of the SOA and M7 designs were found to be essentially the same, and the performance of the M7 corner post design was found to perform better than the SOA corner post design. This difference in performance comes from the sidewall support in the M7 design, which is not present in the SOA design. The designs are capable of gracefully deforming in the post-buckling regime. This mode of deformation with subsequent failure helps assure that in the event of a collision with an object that is fouling a cab car in the push-mode of operation the operator is protected from bulk crushing.

Both designs were developed to be compliant with applicable FRA regulations [1] and APTA standards [2]. Both designs provide improved crashworthiness protection over older designs compliant with minimum FRA requirements. Preliminary observations are:

- the graceful crush of cab car end frames can be objectively measured by large-deformation quasi- 
static testing and by large-deformation dynamic testing, however

- further quasi-static and dynamic tests are necessary to validate quasi-static and dynamic analyses.

\section{APPENDIX - MODEL DESCRIPTIONS}

Two detailed finite element models were developed to investigate both the quasi-static large deformation behavior and dynamic behavior of the prototype SOA end frame design retrofitted onto a Budd Pioneer passenger car and an M7 cab car end frame design. The SOA model incorporated the first twenty feet of the car structure. The M7 model incorporated the first fifteen feet of the car. The cars were modeled using 4 node reduced integration shell elements in ABAQUS EXPLICIT [16]. The characteristic element length in the coarse regions of the two models was approximately 2 inches while in the fine regions it was approximately between 0.25 and 0.5 inches. The SOA model was constructed from 160,005 elements while the M7 model used 123,470 elements. Both models were fully fixed at the rear of the structure. Nonstructural components were not included in these models. Figure 20 depicts the two models developed. Stresses, strains, and displacements of key components were outputted.

The steel coil was modeled as a rigid object using rigid shell elements. The rigid coil was constructed from 17,940 elements. The diameter of the steel coil is 62.5 inches and the length of the coil is 52 inches. The coil was assigned a weight of 41,300 lbf. The coil is assigned a longitudinal velocity and is then free to translate and rotate freely during the simulated impact. The three dimensional accelerations, velocities and displacements were outputted.

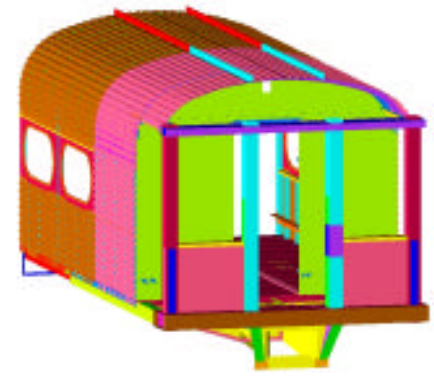

SOA Design

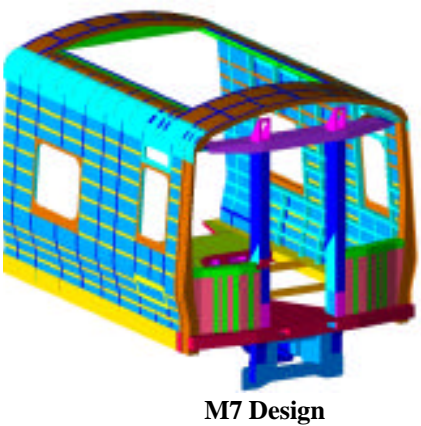

Figure 20. Models Developed of Prototype SOA and M7 End Frame Designs

The appropriate choice of material models is extremely important in obtaining accurate results. An elastic-plastic material constitutive model was used with kinematic hardening for all metal materials in the two models. There were three key materials used for the SOA model and three used for the M7 model. The advantage with the SOA model is that tensile coupon testing was conducted on two of the materials after previous full-scale tests and so actual material properties were available. The material used to make up the most of the end frame components was an A710 class 3 steel. Material certification sheets were provided for the various thickness steel sheets used. The model of the M7 car used only the nominal properties as a start. The model predicted much closer results with the quasi-static tests when the end frame material was enhanced by ten percent.

Currently material failure is modeled in many finite-element analysis packages using a simple strain-to-failure criterion. When the total strain on an element reaches an input value, that element is removed from the mesh. This approach works well when the principal cause of material failure is tension and the extent of material failure is limited. Limitations of the current approach to modeling material failure include the fact that materials fail at different strains in tension than in compression, than in shear [17] and the fact that once material failure has initiated, lower strain is needed to propagate the failure [18].

Sophisticated application of current finite-element analysis packages allow these limitations to be overcome to some degree. By first running the model without material failure, the areas of high strain and potential material failure can be found. The model then can be run again with the parameters associated with material failure adjusted to account for the stress state of the high-strain areas. If the three-dimensional stress state of two or more high-strain areas substantially differ - for example, one in tension and one in compression - then the model can be sub-structured and different material-failure parameters applied to each substructure. An effort is currently underway to better understand material failure under a wide-range of strain states and to develop algorithms that more accurately predict material failure [19].

The definition of alternative failure strains was applied for both models. Areas subjected to severe compressive deformations were assigned a failure strain equal to 0.5 . The SOA model applied a failure strain of 0.3 at the connections of both the buffer/end beam and at the anti-telescoping plate. At the point of load application the 0.5 failure strain was used. The failure strain chosen was based upon the results from preand post-test analyses conducted in $[13,15]$. Excellent agreement was obtained with the locations where material failure was observed and predicted. A lower strain to failure value was used for the M7 model, 0.225. This value was also chosen to obtain good agreement between the predicted and observed locations of material failure on from the quasi-static testing.

\section{ACKNOWLEDGEMENTS}

The dynamic testing and all of the analyses described in this paper were conducted under the Equipment Safety Research Program sponsored by the Office of Research and Development of the Federal Railroad Administration. The authors would like to thank Dr. Tom Tsai, Program Manager, and Claire Orth, Division Chief, Equipment and Operating Practices Research Division, Office of Research and Development, Federal Railroad Administration, for their support.

The quasi-static testing described in this paper was performed as part of the M7 design development conducted for Long Island Rail Road and for Metro-North Rail Road. The authors would also like to thank Mathieu Perrault Director of the Structure and Truck Engineering Department, Mario Raymond, Chief of Service of Structure Department, and Virgilio Hilario, Staff Engineer from the Structure and Truck 
Engineering Department from Bombardier for their ready exchange of technical information and discussions pertaining to the post-collapse behavior of end frame components under large deformations. Bombardier provided a linear elastic model and drawings from which the M7 non-linear plastic model was constructed.

Dr. Richard Stringfellow, Senior Engineer and Patricia Llana, Staff Engineer, Tiax, LLC constructed the SOA finite element model, starting from a model of the Pioneer passenger car developed by Dr. Steven Kirkpatrick from ARA, Inc.

The views expressed are exclusively those of the authors.

\section{REFERENCES}

[1] U.S. Department of Transportation, Federal Railroad Administration, "49 CFR Part 216 et al, Passenger Equipment Safety Standards; Final Rule”, May 12, 1999.

[2] American Public Transportation Association, Member Services Department, Manual of Standards and Recommended Practices for Passenger Rail Equipment, Issue of July 1, 1999.

[3] American Public Transportation Association, Member Services Department, Manual of Standards and Recommended Practices for Passenger Rail Equipment, Issue of May 1, 2004.

[4] Mayville, R., Johnson, K., Tyrell, D., Stringfellow, R., "Rail Vehicle Cab Car Collision and Corner Post Designs According to APTA S-034 Requirements," American Society of Mechanical Engineers, Paper No. MECE2003-44114, November 2003

[5] Cothen, G., Schulte, C., Horn, J., Tyrell, D., 'The FRA and Consensus Rulemaking, TR News, Transportation Research Board, Number 236., January-February 2005.

[6] National Transportation Safety Board, "Collision of Northern Indiana Commuter Transportation District Train 102 with a Tractor-Trailer Portage, Indiana June 18,1998", RAR99-03, 07/26/1999.

[7] National Transportation Safety Board, "Collision of Reading Company Commuter Train and Tractor-Semitrailer, Near Yardley Pennsylvania, June 5, 1975," RAR-76-4, 03/03/1976.

[8] National Transportation Safety Board, "Railroad Accident Report Near Head-on Collision and Derailment of Two New Jersey Transit Commuter Trains Near Secaucus, New Jersey February 9, 1996", RAR-97-01, 03/25/1997.

[9] National Transportation Safety Board, "Collision and Derailment of Maryland Rail Commuter MARC Train 286 and National Railroad Passenger Corporation AMTRAK Train 29 Near Silver Spring, MD February 16, 1996", RAR-97-02, 06/17/1997.

[10] Tyrell, D., Severson, K., Perlman, A.B., March, 2000, "Single Passenger Rail Car Impact Test Volume I: Overview and Selected Results," U.S. Department of Transportation, DOT/FRA/ORD-00/02.1, March 2000.

[11] Tyrell, D., Severson, K., Perlman, A.B., "An Overview of Passenger Equipment Full-Scale Impact Tests: Results to Date," World Congress on Railway Research, Cologne, Germany, November 2001.
[12] Tyrell, D., Severson, K., Perlman, A.B., Rancatore, R., "Train-to-Train Impact Test: Analysis of Structural Measurements," American Society of Mechanical Engineers, Paper No. IMECE2002-33247, November 2002.

[13] Jacobsen, K., Tyrell, D., Perlman, A.B., "Rail-Car Impact Tests with Steel Coil: Car Crush," American Society of Mechanical Engineers, Paper No. JRC2003-1655, April 2003.

[14] Hanefi, E.H., and T. Wierzbicki, "Calibration of Impact Rigs for Dynamic Crash Testing," Joint Research Center, European Commission Institute for Safety Technology, Report EUR 16347 EN, 1995

[15] Martinez, E., Tyrell, D., Zolock, J., "Rail-Car Impact Tests with Steel Coil: Car Crush," American Society of Mechanical Engineers, Paper No. JRC2003-1656, April 2003.

[16] ABAQUS/Explicit Users Manual, Version 6.4, 2003, Hibbitt, Karlsson and Sorenson, Inc.

[17] Bao, Y. and Wierzbicki, T., "Determination of Fracture Locus for the 2024T351 Aluminum," Impact and Crashworthiness Laboratory, Report No. 81, May 2002.

[18] Bao, Y., and Wierzbicki, T., "Comparative Study of Fracture Criteria: Part II - Finite Element Analysis,” Impact and Crashworthiness Laboratory, Report No. 67, November 2001.

[19] Volpe Center Contract DTRS57-98-D-00043, Task Order 9: Investigation of Failure Mechanisms in Railroad Equipment Structures, with Massachusetts Institute of Technology, issued October, 2002. 